\title{
Thermo-hydraulic analysis of the windowless target system
}

\author{
Fosco Bianchi $^{\mathrm{a}, *}$, Roberta Ferri $^{\mathrm{b}}$, Vincent Moreau ${ }^{\mathrm{c}}$ \\ ${ }^{\text {a }}$ ENEA, Via Martiri di Monte Sole 4, 40129 Bologna, Italy \\ b SIET, Via Nino Bixio 27, 29100 Piacenza, Italy \\ ${ }^{\mathrm{c}}$ CRS4, Polaris Edificio 1 CP25, 09010 Pula (CA), Italy
}

Received 2 March 2007; received in revised form 22 October 2007; accepted 22 October 2007

\begin{abstract}
The target system, whose function is to supply an external neutron source to a subcritical core in order to sustain the neutron chain reaction, is the most critical part of an ADS being subject to severe thermo-mechanical loading and material damage due to accelerator protons and fission neutrons.

In order to reduce the material damage and to increase the life of the target system a windowless option was chosen in the framework of the European PDS-XADS project as reference configuration for the experimental ADS cooled by lead-bismuth eutectic alloy.

This document deals with the results of the thermo-hydraulic analysis performed with STAR-CD and RELAP5 codes to assess the behaviour of the windowless target system during off-normal operating conditions. It also reports a description of modifications properly implemented in the codes for studying this kind of plant.

The windowless target system shows a satisfactory thermo-hydraulic behaviour for the analysed accidents, except for the loss of both pumps without proton beam shut-off and for the beam trips lasting more than $1 \mathrm{~s}$.
\end{abstract}

(C) 2008 Elsevier B.V. All rights reserved.

\section{Introduction}

An ADS is a promising solution for reducing the long-term radio-toxicity and the amount of long-lived radionuclides to be disposed in a safe manner. It consists of a subcritical system coupled to an accelerator by means of a target system. In fact, a subcritical system is not able to sustain by itself the neutron chain reaction, but it needs an external neutron source that is produced by the interaction of a proton beam coming from an accelerator with a heavy metal target located inside a target system in order to limit the pollution of spallation products in the primary system.

Abbreviations: ADS, accelerator driven system; EC, European commission; DBCs, design basis conditions; DECs, design extension conditions; ETWG, European technical working group; HX, heat eXchanger; IHX, intermediate heat eXchangers; LBE, lead-bismuth eutectic alloy; LLFP, long-lived fission products; MA, minor actinides; MLD, master logic diagram; PDS-XADS, preliminary design study on an eXperimental accelerator driven system; RVACS, reactor vessel air cooling system; XADS, eXperimental accelerator driven system.

* Corresponding author. Tel.: +39 051 6098426; fax: +390516098279.

E-mail address: fosco.bianchi@bologna.enea.it (F. Bianchi).
A subcritical system does not rely on delayed neutrons for the control or power change, but it is only driven by a spallation neutron source, thus control rods and reactivity feedback have very little or no importance.

Thanks to the subcriticality, an ADS can: (1) be safely operated with any fuel (also with a high concentration of MA); (2) take advantage of the nuclear properties of the lead-bismuth eutectic (LBE) alloy, used as coolant, for effectively burning nuclear waste; (3) facilitate tasks that would be difficult or inefficient in critical systems ${ }^{1}$.

A detailed analysis of the technical issues critical for the development of ADSs was performed during the elaboration of the European Roadmap by the ETWG, which clearly indicated the need to design and operate a plant at a sufficiently large scale to become a precursor of an industrial transmuter (Rubbia et al., 2001).

A great amount of $R \& D$ and engineering activities oriented to the development of basic aspects of ADS concepts was per-

\footnotetext{
1 An ADS may be suited as "incinerator" of material that burns poorly or not at all in thermal reactors or/and makes more difficult the reactivity control system of fast reactors.
} 
formed in the 5th EC Framework Programme on Partitioning and Transmutation. In particular, the PDS-XADS project was aimed at demonstrating the coupling feasibility of an accelerator with a subcritical system and at investigating the transmutation capability of a core totally charged with innovative MA-dedicated assemblies (Carluec, 2003). Three options were considered and studied: two large XADS concepts of $80 \mathrm{MW}$ thermal power respectively cooled by LBE and gas (He) and a small LBEcooled XADS of approximately 50MWth, called MYRRHA, (Carluec and Jardì, 2003).

The large LBE-cooled XADS is a pool-type design similar to the solution adopted for most sodium-cooled reactors (Cinotti et al., 2003a). This concept has the advantage to be characterized by a large thermal capacity and to contain all the primary coolant inside the vessel, thus eliminating the problems deriving from the out-of-vessel coolant transport.

The primary LBE circulation relies on natural circulation enhanced by injection of argon gas fed by a compressor into the bottom part of 24 vertical riser pipes installed over the periphery of the above core structure, Fig. 1. Due to the adopted design solutions, such as high fuel pin pitch-to-diameter ratio, absence of mechanical pumps and low coolant velocities, the hydraulic resistance of the primary circuit is very low (about $30 \mathrm{kPa}$ ). Consequently a high level of natural circulation is assured even in case of failure of the gas-lift pumps.

The primary coolant flowing out of the core collects in the hot plenum, enters the riser pipes and goes to the downcomer uppermost region, then it flows from top to bottom in the lower plenum and enters the core as well as the target system, Fig. 1. The major part of the coolant flows in the downcomer through the IHX, transferring heat to the secondary fluid. A small fraction of the coolant flows down through the IHX bypass, transferring heat to the RVACS, which removes $\sim 260 \mathrm{~kW}$ of power under nominal conditions and is also able to assure the decay heat removal in the event of unavailability of both secondary loops.

The subcritical core has an annular configuration around the target system vessel and it consists of 120 MOX fuel assemblies of two different enrichments, 168 dummy assemblies and 12 absorber devices (Bianchi et al., 2006).

The heat generated in the core and target is transferred to the environment by two secondary loops thermally coupled to the primary system through four IHX. The secondary coolant is organic oil, as no electric power production is envisaged in the system.

The main design parameters of the primary system are summarized in Table 1.

The target system is the most critical part of an ADS being subject to severe thermo-mechanical loading and material damage due to accelerator protons and fission neutrons irradiation. In order to overcome the issues related to material structural resistance, in particular of the window, and therefore to increase the target life, a windowless option was chosen as reference solution for the LBE-cooled XADS, because the proton beam directly impinges on the LBE free surface and no structural materials is exposed to the direct proton irradiation.

A transient analysis, oriented to define enveloping conditions to be used for the thermo-mechanical verifications and to assess

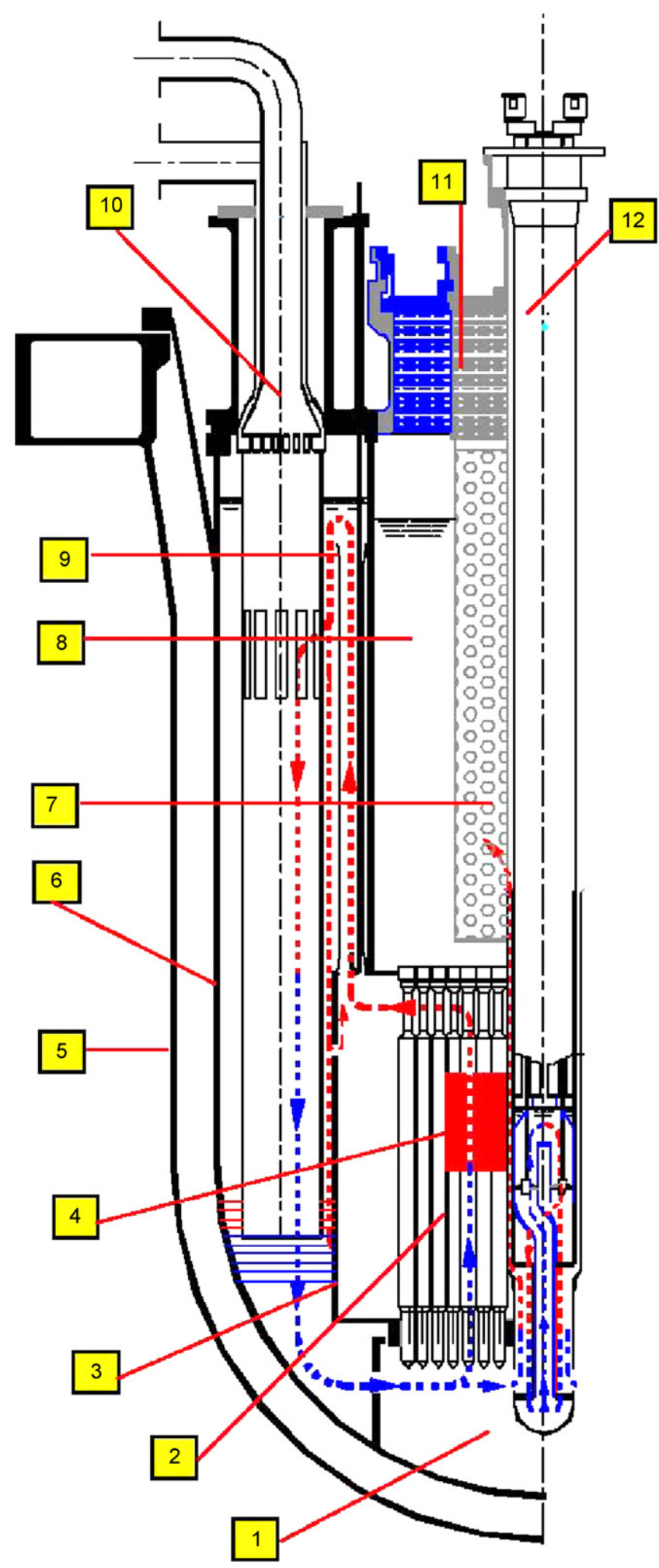

Fig. 1. XADS reactor assembly reference configuration: 1: lower plenum; 2: reactor core; 3: inner vessel; 4: fuel assemblies; 5 : safety vessel; 6: reactor vessel; 7: above core structure (lower part); 8: dead volume; 9: risers; 10: intermediate heat exchanger; 11: above core structure (upper part); 12: target system. 
Table 1

Main primary system process parameters

\begin{tabular}{lc}
\hline Parameter & Value \\
\hline Core thermal power $(\mathrm{MW})$ & 80 \\
Primary flow rate $(\mathrm{kg} / \mathrm{s})$ & 5961 \\
Core flow rate $(\mathrm{kg} / \mathrm{s})$ & 5410 \\
Core by-pass flow rate $(\mathrm{kg} / \mathrm{s})$ & 340 \\
Core inlet temperature $(\mathrm{K})$ & 573 \\
Core outlet temperature $(\mathrm{K})$ & 673 \\
Argon injection flow rate $(\mathrm{N}-1 / \mathrm{s})$ & 120 \\
IHX exchanged power $(\mathrm{MW})$ & 20.75 \\
Core pressure loss $(\mathrm{KPa})$ & 25 \\
Primary system pressure loss $(\mathrm{KPa})$ & 29 \\
Secondary fluid flow rate $(\mathrm{kg} / \mathrm{s})$ & 827 \\
Secondary fluid temperature at IHX inlet $(\mathrm{K})$ & 543 \\
Secondary fluid temperature at IHX outlet $(\mathrm{K})$ & 585 \\
\hline
\end{tabular}

the behaviour of the target system during DBCs and DECs, was carried out using RELAP5 and STAR-CD codes.

To this purpose, a set of enveloping transient initiators was selected hypothesizing malfunctions of the accelerator and failures of the target components, even if some of them may be characterized by a very low probability of occurrence on the verge of credibility.

This document deals with the results of the thermo-hydraulic numerical simulations performed with the above-mentioned codes for studying the behaviour of the windowless target system during off-normal operating conditions. It also reports a description of modifications properly implemented in the codes, as necessary for assessing the ADS behaviour during normal and accidental conditions.

\section{Windowless target system}

The windowless target system has a vertical orientation and penetrates the reactor vessel cover plate and the core from the top by a non-axial central channel, Fig. 2. It is supported at the reactor vessel top and horizontally guided at the elevation of the core diagrid, Fig. 1, thus it is free to axially expand as needed owing to thermal expansion as well as deformation resulting from mechanical loads (Cinotti et al., 2003b).

LBE is used in the target system both as target and as a means of transferring the heat deposited by the impinging proton beam to the heat sink placed about $1 \mathrm{~m}$ beneath the core region. Because of the basic conception of the windowless target, natural circulation is inherently hindered, the cold source being at lower position with respect to the hot one. Therefore, a continuous LBE flow from the free surface towards the heat exchanger can only rely on forced circulation assured by two mechanical pumps, which thrust it upwards into the spallation zone, where it is heated up, and then downwards through the heat exchanger, where it is cooled by the primary coolant.

The in-series arrangement ensures that one pump is able to supply enough flow to avoid abrupt LBE heating in the spallation zone in case of failure of the other pump.

The heat exchanger, placed at bottom of the target system fitting in the central core cavity, is a classic tube shell HX with the target LBE flowing down inside the assembly tubes and the primary LBE flowing counter-current outside the tubes from the core feed up to the quasi-stagnant region above the core (dead volume), Figs. 1 and 2. An inner duct drives back LBE from the HX lower plenum to the spallation zone.

The proton beam footprint is shaped as rectangular very thin in the flow direction, about $1 \mathrm{~cm}$ thick, and a little smaller than the channel width in the other direction $(8 \mathrm{~cm})$. Consequently, the spallation volume is roughly bounded by a slab $8 \mathrm{~cm}$ wide, $1 \mathrm{~cm}$ thick and $30 \mathrm{~cm}$ deep through the target LBE, with the Bragg peak located at the end of the beam range $(29 \mathrm{~cm})$.

The size of the target system is mainly based on a balanced optimization among neutronic aspects (neutronic efficiency) and thermo-hydraulic constraints resulting from the large value of beam energy released in the spallation volume, the maximum target LBE flow velocity and temperature distribution.

The proton beam energy being $600 \mathrm{MeV}$, the energy released as heat is about $72 \%$ of the total: the rest is shared between the particles escaping the system and the binding energy of target nuclei. Therefore the heat that needs to be removed by the target cooling system is $2.6 \mathrm{MW}$, which corresponds to an average density power of $12.5 \mathrm{~kW} / \mathrm{cm}^{3}$, considering the above-mentioned dimension of the spallation volume.

Potential LBE boiling due to a high concentrated power of the beam spot impinging in the bulk is avoided by a simple beam scanning along a fixed line segment at high frequency $(200 \mathrm{~Hz})$. This solution also allows to eliminate potential LBE local over-heating at the scanning edges, where the beam motion is reversed.

The peak temperature in the spallation volume is kept quite below the LBE boiling point to avoid massive boiling and disruption of the cooling configuration thanks to a suitable flow velocity profile inside the LBE depth, along the beam range. This profile also assures that possible onset of limited hot spots or local boiling in superheated thin flow fillets do not rise buoyancy thrust and extinguish inside the LBE bulk while flowing downstream towards the heat exchanger.

The maximum LBE flow velocity at free surface of the spallation zone is kept high enough in order to limit the maximum LBE surface temperature and the related LBE evaporation rate (as well as of other volatile spallation products) into the vacuum beam pipe, but below $2 \mathrm{~m} / \mathrm{s}$ to keep corrosion low.

Table 2 summarizes the main process parameters of the target system and Table 3 shows the design limits for LBE and the selected target structures material.

\section{Transient analysis}

This analysis was oriented to assess the thermo-hydraulic behaviour of the target system during DBCs and DECs and to provide a set of boundary conditions allowing 3D simulations of the spallation zone in order to define enveloping conditions to be used for the thermo-mechanical verifications.

Two codes were used for these analyses: STAR-CD and RELAP5 mod. 3.2 beta version (Shich et al., 1998). The former was used to study the stability and the thermo-hydraulics of the LBE flow in the spallation zone and to simulate the ther- 


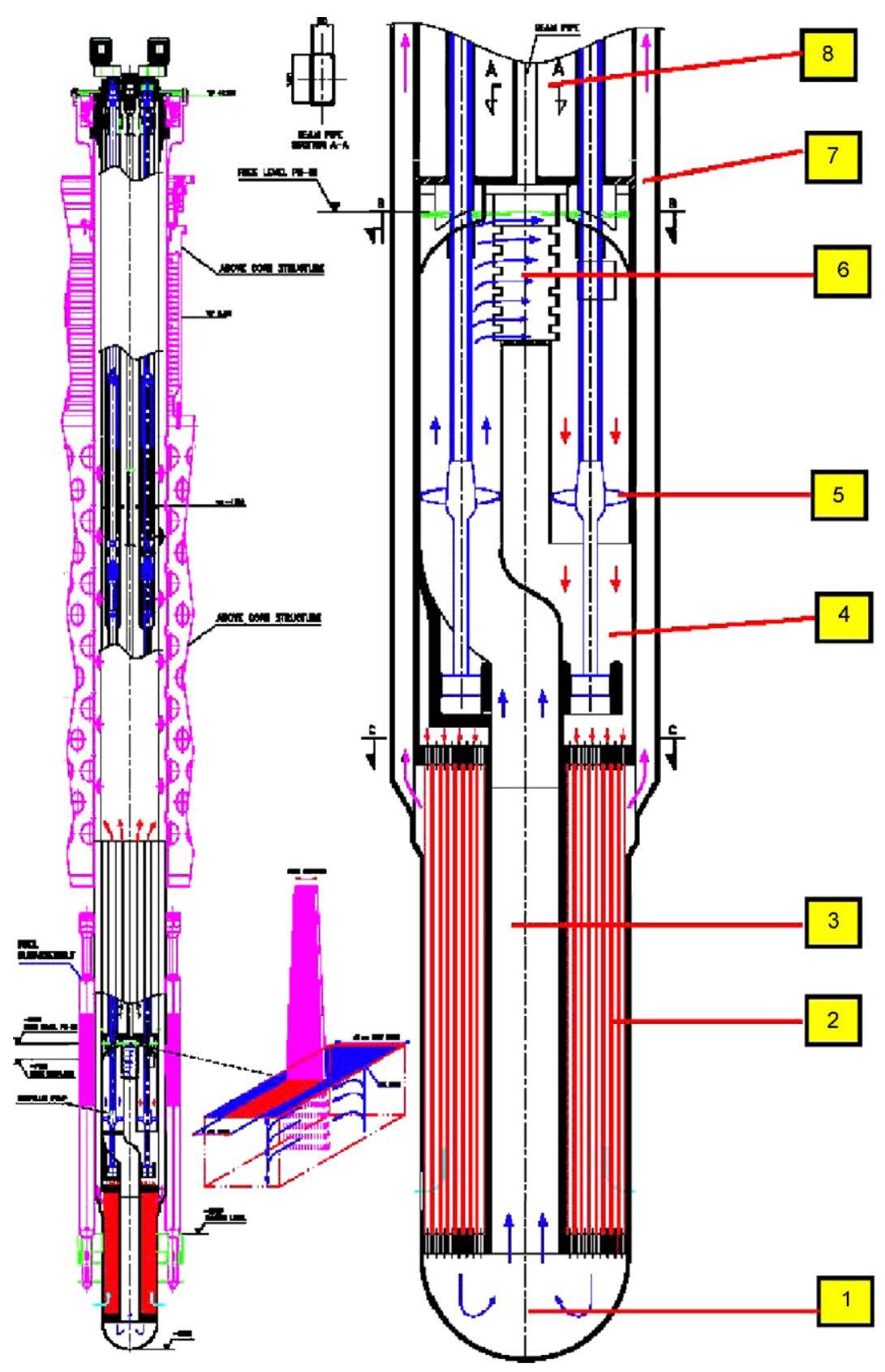

Fig. 2. Target system sketch: 1: Cold plenum; 2: heat exchanger; 3: rising channel; 4: descending channel; 5: axial pump; 6: spallation zone; 7: cooling channel; 8: LBE stagnant region above spallation zone.

mal behaviour of the target above the two pumps, the latter for assessing the thermo-hydraulic behaviour of the target system and the subcritical system and for providing input data for STARCD calculations. In particular RELAP5 code required relevant modifications to use LBE as working fluid and to simulate airs coolers, such as development and implementation of thermodynamic properties (enthalpy, etc.) and other physical properties (thermal conductivity, surface tension and viscosity); implementation of heat transfer correlations and development of the finned tube heat exchanger model. The modifications were validated against the results of the ETGAR-3 (EI-Boher et al., 1988) and CHEOPE (Bianchi et al., 2002) experimental tests and Russian codes for LBE heat transfer calculations.

\subsection{System models}

The RELAP5 model of the target system, shown in Fig. 3, is thermally and hydraulically coupled to the primary system model (Bianchi et al., 2004) by means of the target cooling channel that drives the primary LBE from the lower plenum up to the quasi-stagnant zone above the core. It simulates the rising channel with the first pump, the spallation zone (vol. 208, 209, 210 from top to bottom), the descending channel with the second pump, the HX and the downcomer channel.

The LBE stagnant region above the spallation zone (vol. 228) is connected to the cooling channel and the quasi-stagnant region above the core by means of small holes suitable to the circuit 
Table 2

Main target system process parameters

\begin{tabular}{ll}
\hline Parameter & Value \\
\hline Max. proton energy $(\mathrm{MeV})$ & 600 \\
Max. proton beam intensity (mA) & 6 \\
Max. deposited power/beam power (MW) & $2.6 / 3.6$ \\
Current density profile of the beam spot & Gaussian \\
Target rising channel flow rate $(\mathrm{kg} / \mathrm{s})$ & $\sim 208$ \\
Primary HX flow rate $(\mathrm{kg} / \mathrm{s})$ & $\sim 266$ \\
LBE temperature $(\mathrm{K})$ & \\
$\quad$ Target spallation zone inlet & 608 \\
Target spallation zone oulet & $\sim 713$ \\
Primary HX inlet & 573 \\
Primary HX outlet & 653 \\
Target LBE velocity (m/s) & \\
Flow average & 0.5 \\
Maximum at the free surface & $\leq 2.0$ \\
\hline
\end{tabular}

fill-up at the beginning of the plant set-up. The stagnant LBE volume has a free surface level corresponding to the XADS primary circuit one.

The dimensions of volumes of the spallation zone and the rising and descending channels were chosen in order to reduce as much as possible the errors related to the data transfer from the RELAP5 model to the STAR-CD one.

The STAR-CD model was instead limited to the target system part placed between the two pumps and the upper plate that separates the spallation zone from the LBE stagnant region. It includes the pump shafts, the duct walls and the horizontal plate located in the downcomer channel at an elevation higher than the pump outlet in order to allow a small fluid recirculation in the upper part to limit the temperature difference between inside and outside the spallation zone. The model has 384,000 fluid cells and 181,000 solid cells and it is parametrized so that the mesh density and the position of the characteristic points can be easily modified.

\subsection{Transient results}

The list of off-normal conditions that may be a challenge for the integrity of the target system was identified using the MLD approach, namely by constructing a top-level logic model and then deducing the appropriate set of initiating events.

Table 3

Target design limits

\begin{tabular}{lr}
\hline Parameter & Value \\
\hline LBE fluid flow close to wall $(\mathrm{m} / \mathrm{s})$ & $\leq 2$ \\
Temperature of the free surface $(\mathrm{K})$ & $<723$ \\
Temperature of target materials $^{\mathrm{a}}(\mathrm{K})$ & \\
Without coating $^{\text {With coating }}$ & $<723$ \\
Surface alloying with Al & $<808$ \\
\end{tabular}

${ }^{a}$ For ferritic-martensitic mod. 9Cr1Mo steel (French denomination T91).
This approach was preferred, because of the peculiar characteristics of the XADS plant and the resulting lack of plant specific data as well as of operating data.

The abnormal conditions analysed concerned accelerator beam trips of different length, trip of a target pump with or without proton beam shutdown and trip of two target pumps without proton beam shutdown.

On the basis of the classification rules reported in he European Utilities Requirements, all sequences belong to $\mathrm{DBC}^{2}$, except for the trip of one or two pumps without the accelerator shutdown, respectively classified as $\mathrm{DEC}^{3}$ and Residual Risk conditions ${ }^{4}$. The latter was only analysed for evaluating the grace period, the contemporaneous loss of the two pumps being incredible for the criterion of the single failure.

\subsubsection{Accelerator beam trips}

A series of beam trips of different length followed by power restart was analysed to simulate malfunctions of the accelerator control system.

The analysed scenario assumes that the beam shutdown or trip and the beam restart after the zero-power period last $1 \mathrm{~ms}$. The RELAP5 results show that only beam trips lasting more than $1 \mathrm{~s}$ can affect the fluid and system structures and therefore the proton beam must not be turned on to avoid heavy thermal stresses on the walls. In fact, LBE and structures temperature variations are almost negligible for beam trips lasting less than $1 \mathrm{~s}$ (Bianchi et al., 2004).

Consequently, the STAR-CD calculations were only performed for an instantaneous beam shutdown and a beam trip lasting $1 \mathrm{~s}$ followed by an instantaneous beam restart.

As the target circuit was designed so that the effect of the buoyancy force on the flow is almost negligible during the shutdown and start-up transient (nearly identical flow field with and without the accelerator beam), the analysis was only limited to the thermal transient without any sensible loss of accuracy.

Figs. 4-10 show the temperature field in the fluid and internal structures of the modelled target zone in steady state conditions at full power and at given times of the transient.

It is worth underlining that the fluid temperatures during the beam shutdown achieve the value of the target spallation zone inlet (see Table 1) after $1 \mathrm{~s}$, whereas those of the circuit walls take more than $4 \mathrm{~s}$ to reach this value (large inertia), Figs. 6 and 7. In case of the beam trip lasting $1 \mathrm{~s}$, the LBE temperatures in the spallation zone and in the descending channel, shown in Figs. 8 and 9, reach the steady state values after 1 and $4 \mathrm{~s}$, respectively. On the contrary, the temperature on the walls shows a greater inertia than the temperature in the fluid. It takes about

\footnotetext{
${ }^{2}$ Initiating events covering the whole range of faults from those that may occur several times within the plant life to those whose occurrence is very unlikely, but the consequences must be evaluated with conservative rules.

${ }^{3}$ Events characterized by a low frequency of occurrence and considered in the design with respect to the application of defence-in-depth principle and corresponding generally to multiple failures.

${ }^{4}$ Events with severe consequences that are postulated to be unacceptable and therefore they have not to be analysed. It is only necessary to demonstrate that the prevention measures regarding their occurrence are sufficient.
} 


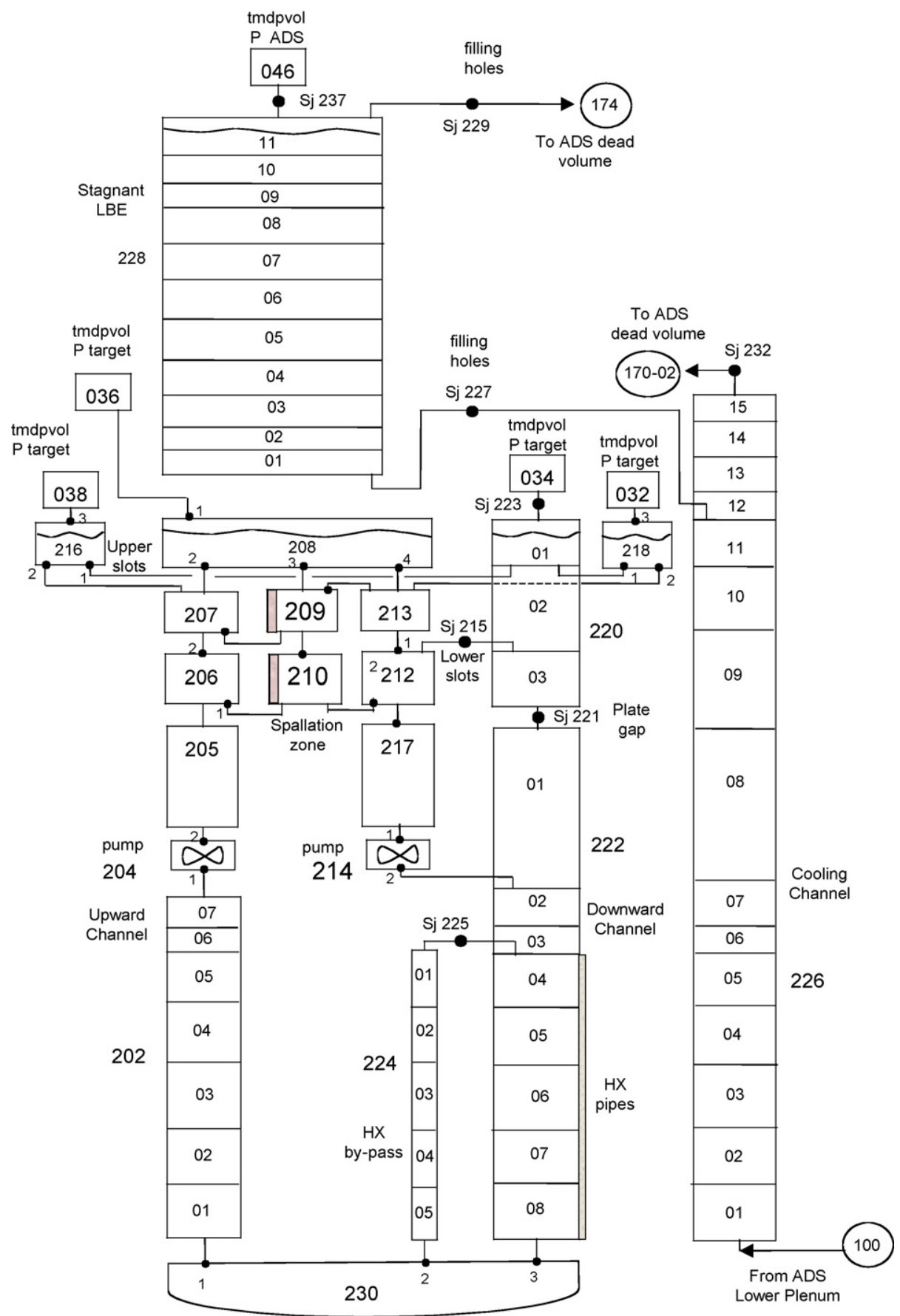

Fig. 3. Target system nodalization.

$4 \mathrm{~s}$ for the internal channel wall to return to the stationary value at the Bragg peak level, while the temperature in the pump axis has still a weak transient behaviour at the end of the simulation, Fig. 10.

\subsubsection{Trip of a target pump (1 out of 2 ) with the} accelerator shutdown

The imposed transient may be divided in three main phases: (I) full power steady state conditions; (II) pump trip and beam shut-off; and (III) quasi-steady conditions at the core decay power.
The accident sequence starts after $1000 \mathrm{~s}$ of steady state operation at full power owing to the trip of the pump located in the rising channel, whose speed was brought to zero in $3 \mathrm{~s}$. The beam shut-off was supposed to occur just after the pump trip start and the beam power was set to zero in $1 \mathrm{~ms}$.

After the accelerator shutdown, the decay power is provided to the subcritical core and the XADS control system adjusts the air coolers flow rate in order to remove it. The power and flow rate in the core and the target system are shown in Figs. 11 and 12, respectively. A primary flow rate decrease of about $300 \mathrm{~kg} / \mathrm{s}$ is observed for about $900 \mathrm{~s}$ due to the air flow rate regulation 

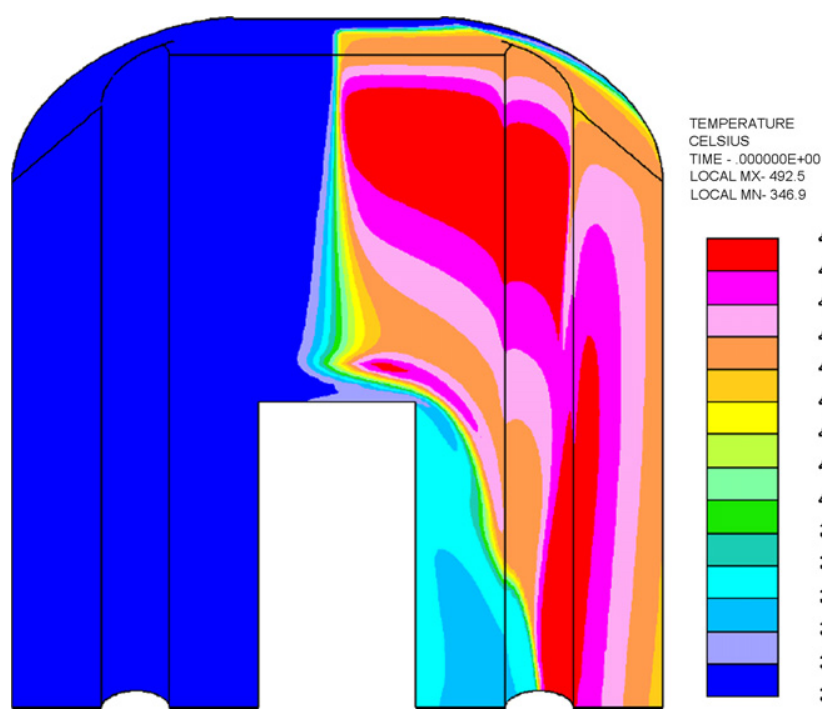

Fig. 4. Steady-state fluid temperatures map.

by the control system, then the flow rate increases and tends toward a steady value of $5390 \mathrm{~kg} / \mathrm{s}$, Fig. 11. The target flow rate quickly reduces from 208 to $143.1 \mathrm{~kg} / \mathrm{s}$, Fig. 12 . After the beam shut-off, the core outlet temperature falls down and after a series of oscillations, the core inlet and outlet temperatures slowly decrease according to the decay power curve maintaining a difference of about $2 \mathrm{~K}$ between them, Fig. 13. The target spallation zone inlet and outlet temperatures and the HX inlet and outlet temperatures (HX LBE and primary LBE) equalise just after the beam trip and they tend to the cold regime condition ones, Fig. 14. Also the spallation zone temperatures reach the same value after the beam trip, Fig. 15.

The analysis of this accident shows that the target and primary system reach quasi-steady conditions following the decay power curve.
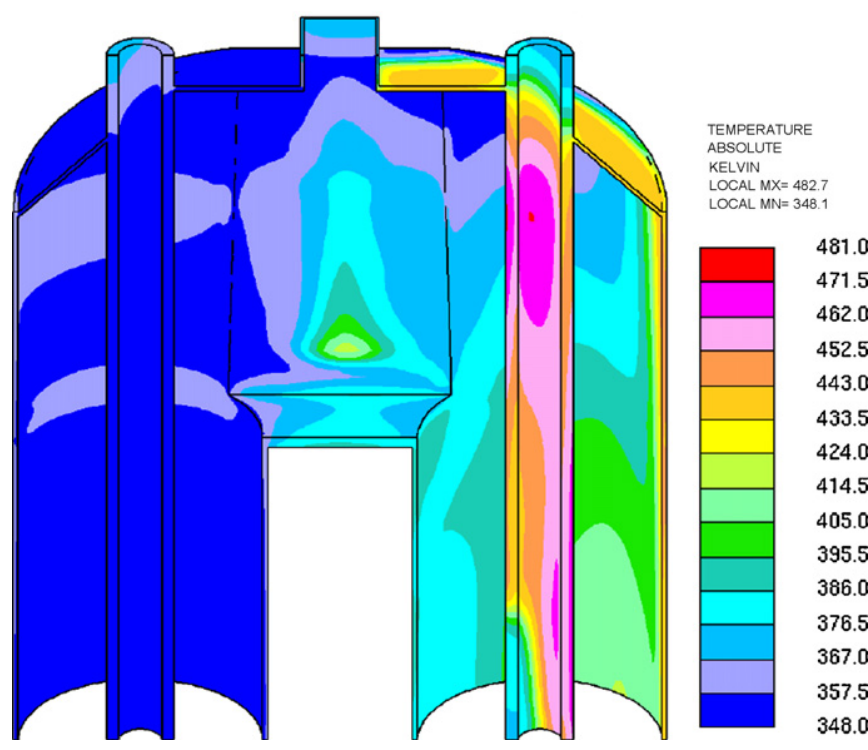

Fig. 5. Steady-state structures temperatures map.

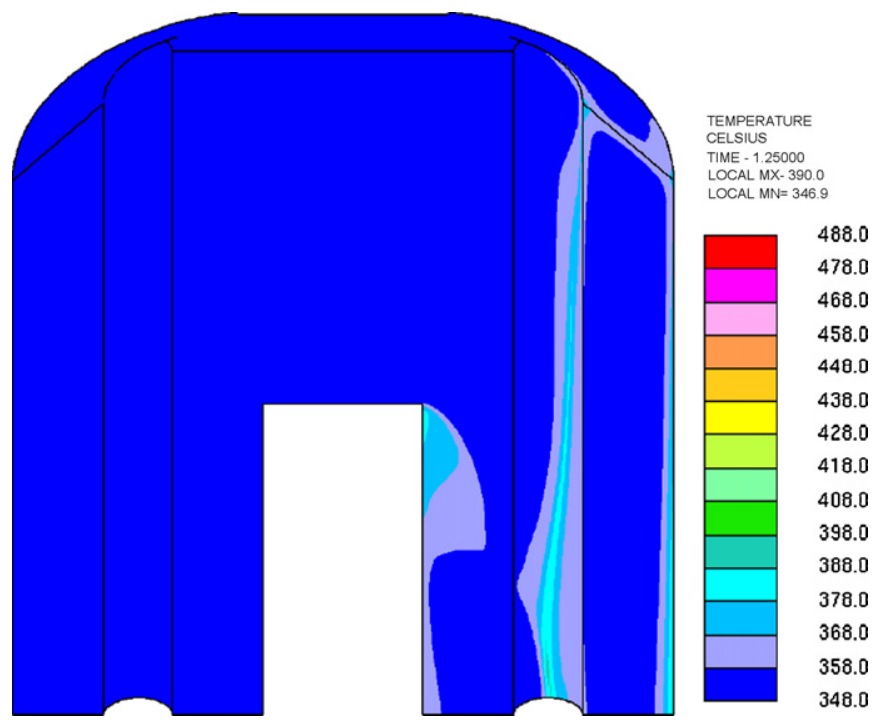

Fig. 6. Beam shutdown: fluid temperatures map at $1.25 \mathrm{~s}$.

\subsubsection{Trip of a target pump without proton beam shut-off} followed by the second pump trip

This accident is very unlikely and was classified as Residual Risk conditions. It was studied for evaluating the grace period of the plant and for providing input data for the first phase of the transient ensuing from the first pump trip, needed for the thermo-mechanical evaluations of the target structures considered critical.

The imposed transient was divided in two parts: the former lasting till $2500 \mathrm{~s}$ for also studying the target and plant behaviour during the unprotected sequence "trip of one target pump without beam shut-off", and the latter (from $2500 \mathrm{~s}$ to the interruption of the calculations at $2716.5 \mathrm{~s}$ ) to evaluate the plant conditions out of control after the second pump trip. It starts from a full power steady state. At time $1000 \mathrm{~s}$, the pump located in the rising channel was tripped and the speed of the pump was brought to

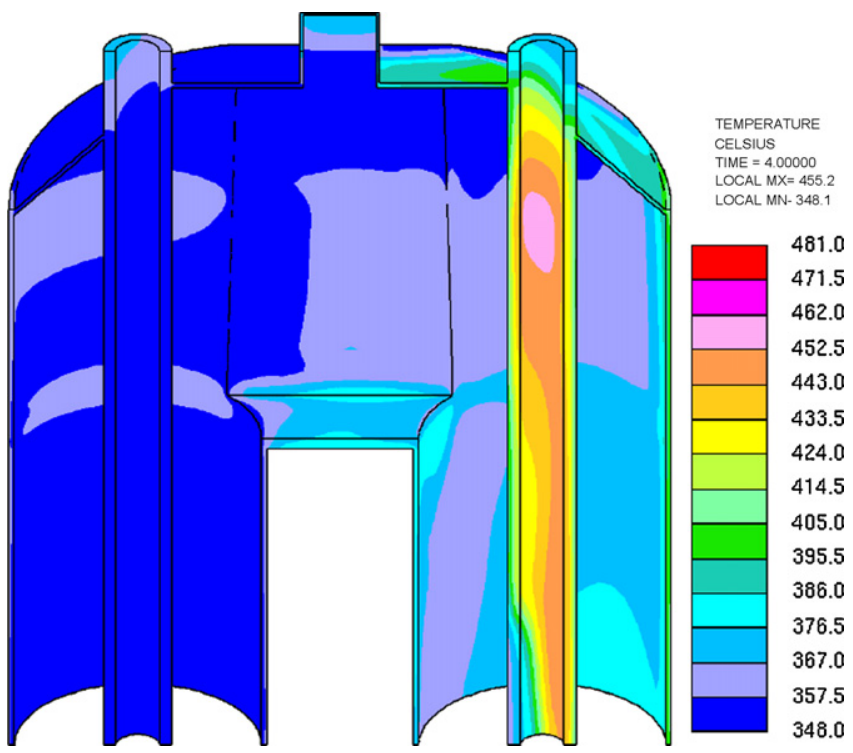

Fig. 7. Beam shutdown: structures temperatures map at $4 \mathrm{~s}$. 

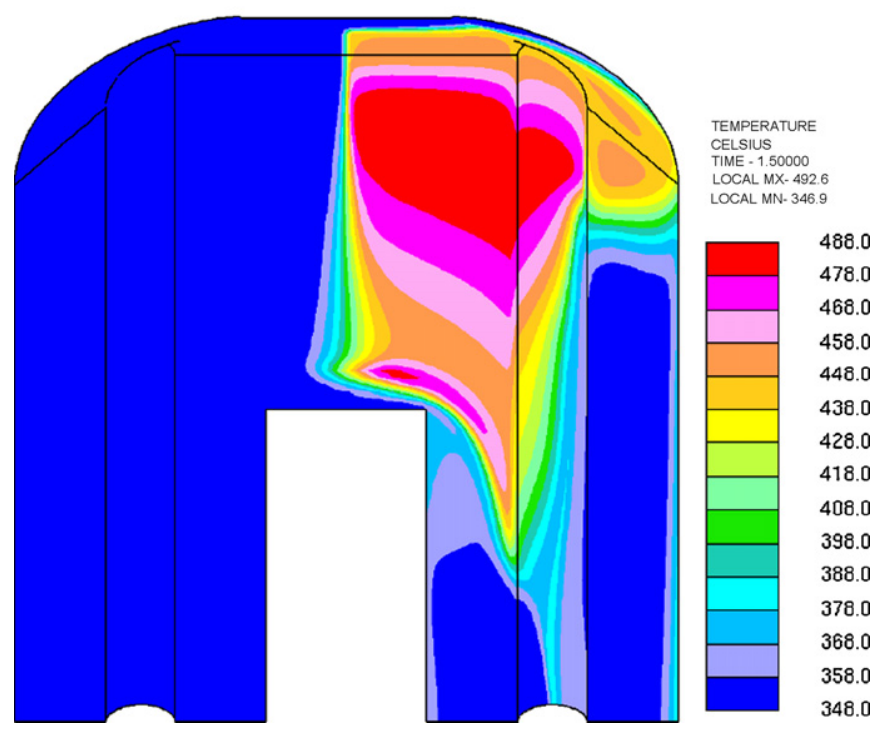

Fig. 8. Beam trip: fluid temperatures map at $1.5 \mathrm{~s}$.

zero in $3 \mathrm{~s}$. The transient is characterized by the following main phases: full power steady state, first pump trip, new steady state conditions, second pump trip, plant condition out of control.

As the accelerator is not shutdown after the first pump trip, no flow regime modification occurs in the primary system consequently to the pump trip and the core inlet and outlet temperatures remain at their original value. Instead the target flow rate quickly reduces from 208 to $130 \mathrm{~kg} / \mathrm{s}$ after the pump trip, Fig. 16. It is worth noting that the target flow rate reduction is larger than that occurring in the case of a pump trip with the accelerator shutdown, because of the natural circulation driving force opposition to the fluid circulation driven by the pump, as the heat source is at the top of the circuit. The inlet and outlet temperatures in the spallation zone decrease and increase, respectively. The temperature increase at the outlet is due to the beam power deposition in a reduced LBE flow rate, whereas

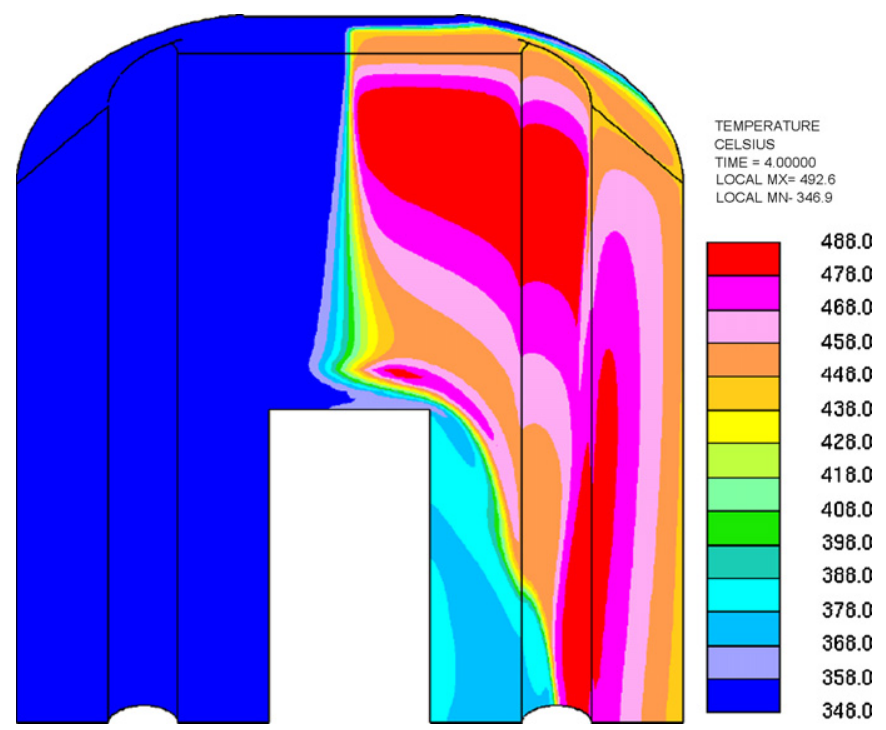

Fig. 9. Beam trip: fluid temperatures map at $4 \mathrm{~s}$.

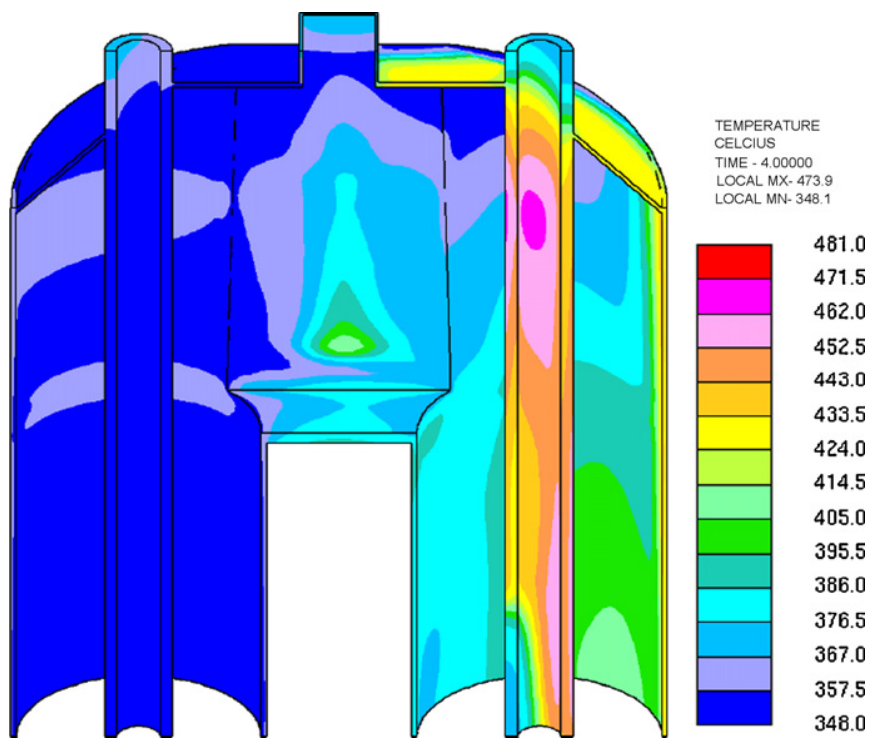

Fig. 10. Beam trip: structures temperatures map at $4 \mathrm{~s}$.

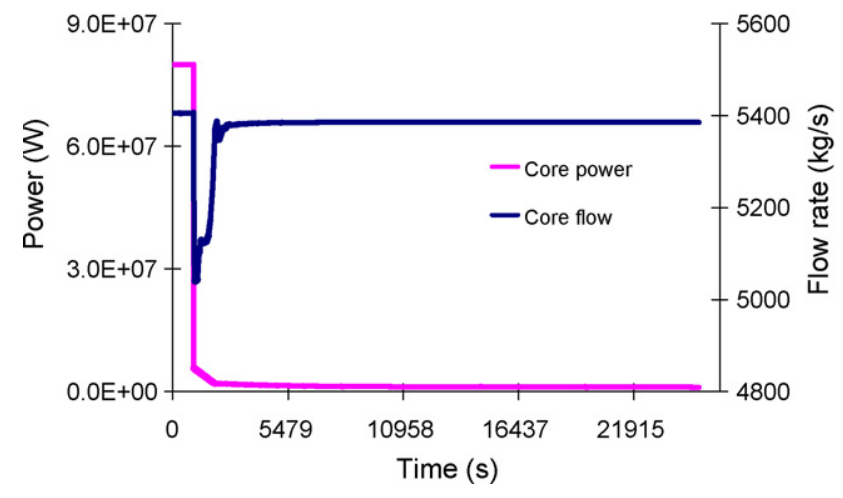

Fig. 11. Core power and flow rate.

the temperature decrease at the inlet depends on the HX power rejection rate. With a reduced flow rate, the power rejection rate to the primary circuit is maintained by increasing the temperature difference between HX inlet and outlet, Fig. 17. The inlet temperature in the HX cooling channel is always constant and equal to the core inlet temperature; the outlet temperature practically remains at its original value, as the cooling channel flow rate after undergoing a small variation just after the pump trip reaches a constant value of $264.3 \mathrm{~kg} / \mathrm{s}$, slightly lower than the ini-

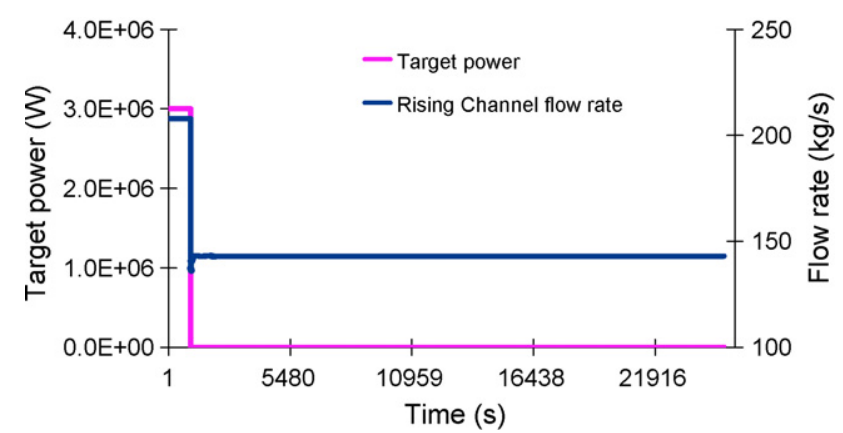

Fig. 12. Target power and rising channel flow rate.

Please cite this article in press as: Bianchi, F., et al., Thermo-hydraulic analysis of the windowless target system, Nucl Eng Des (2008), doi:10.1016/j.nucengdes.2007.10.026 


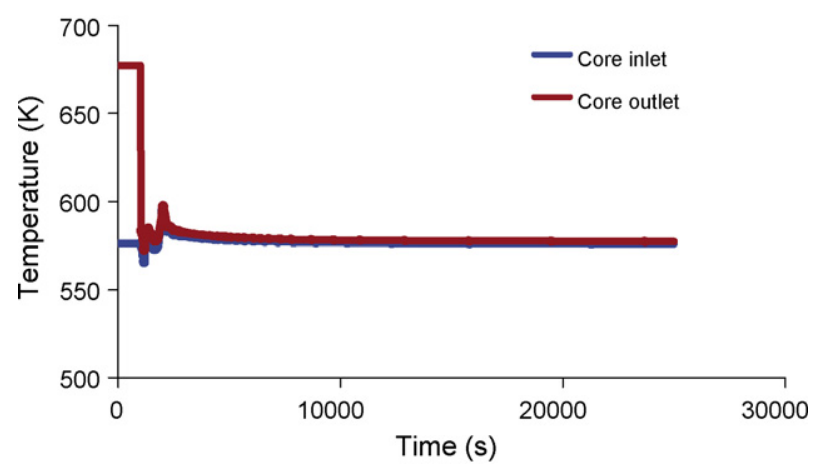

Fig. 13. Core inlet and outlet temperatures.

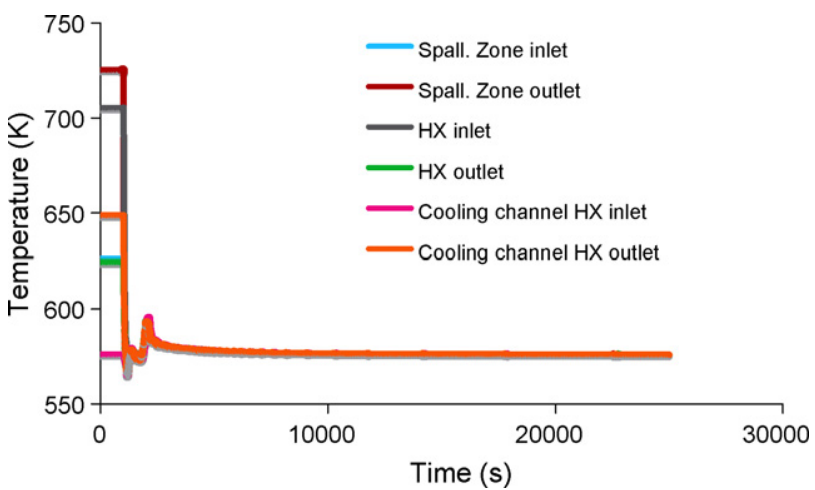

Fig. 14. Spallation zone, HX and cooling channel inlet and outlet temperatures.

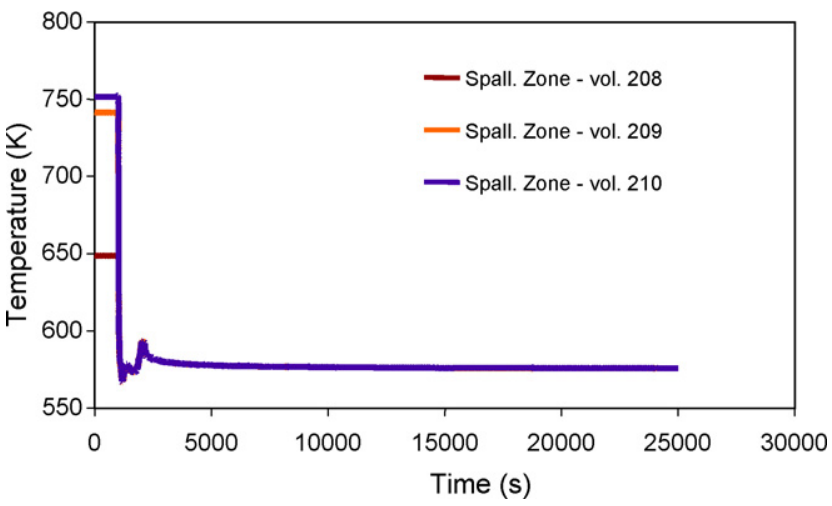

Fig. 15. Spallation zone temperatures.

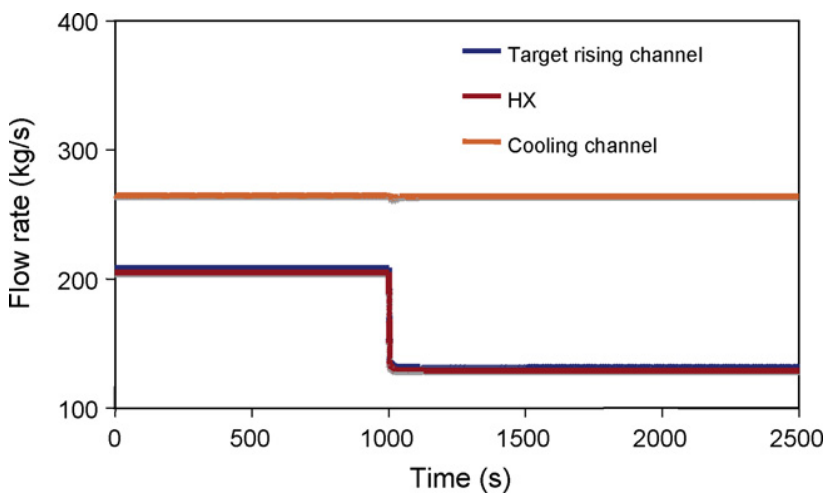

Fig. 16. Target, Rising channel and HX cooling channel flow rates.

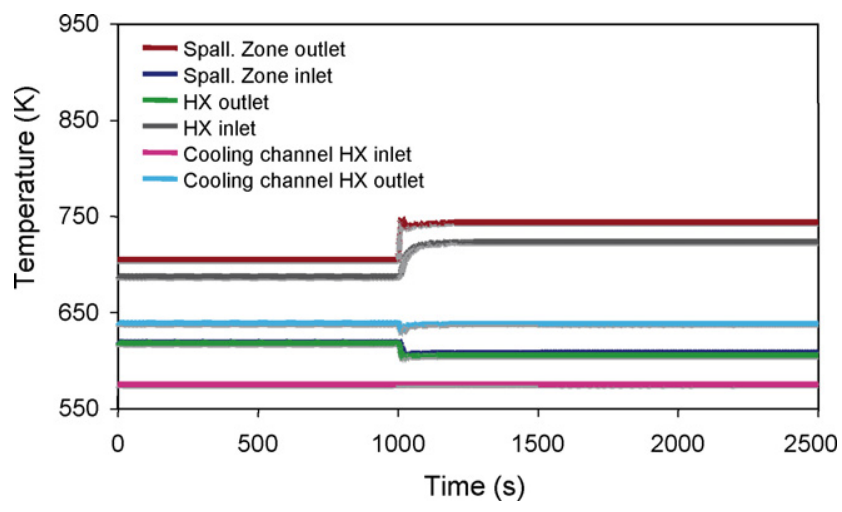

Fig. 17. Inlet and outlet temperatures of the spallation zone, HX and cooling channel.

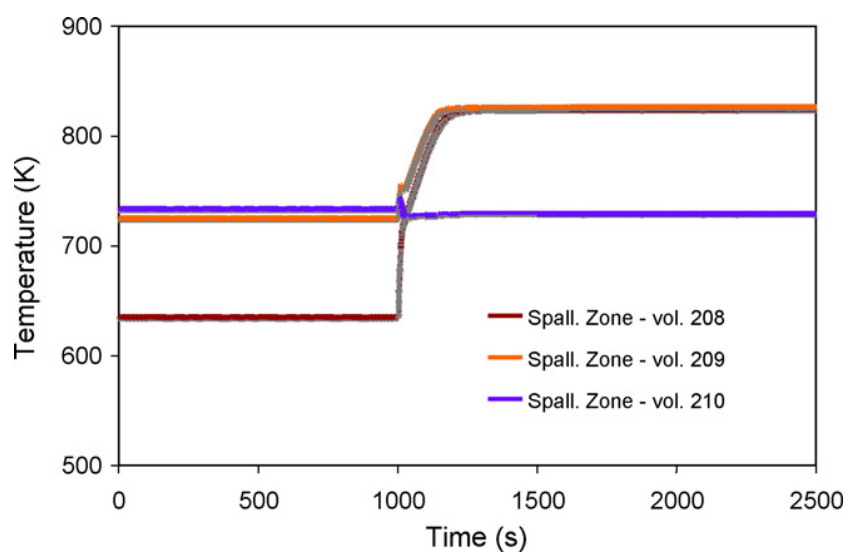

Fig. 18. Spallation zone temperatures.

tial value $(264.7 \mathrm{~kg} / \mathrm{s})$. The spallation zone temperatures, shown in Fig. 18, increase and converge toward a new steady condition characterized by a thermal stratification as a consequence of the flow rate reduction.

After the second pump trip (at time 2700 s), the target flow rate falls to zero and reverts between 2705 and 2714 s reaching a negative peak of about $18 \mathrm{~kg} / \mathrm{s}$, then it becomes positive again, but the calculation stops for high fluid temperature at $2716.5 \mathrm{~s}$, Fig. 19. Owing to this circulation inversion in the spallation zone, the target inlet temperature overcomes the outlet one, Fig. 20, whereas the temperatures in the spallation zone, shown in Fig. 21, increase in particular in the volume where

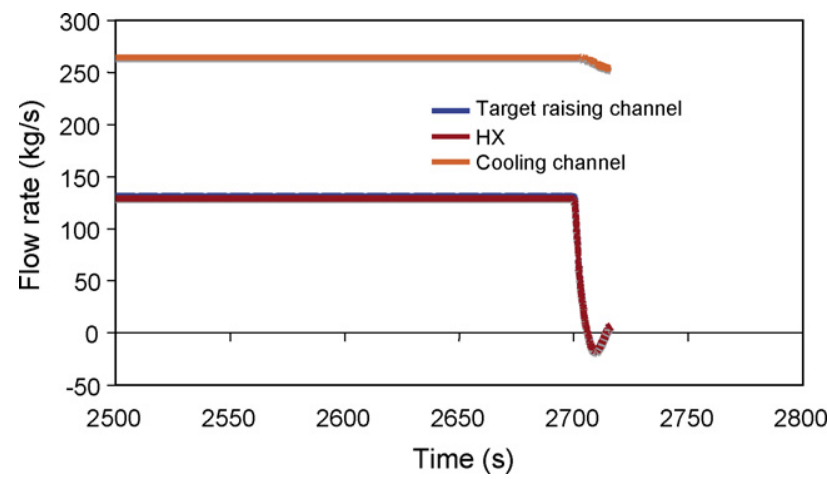

Fig. 19. Spallation zone, HX and cooling channel flow rates.

Please cite this article in press as: Bianchi, F., et al., Thermo-hydraulic analysis of the windowless target system, Nucl Eng Des (2008), doi:10.1016/j.nucengdes.2007.10.026 


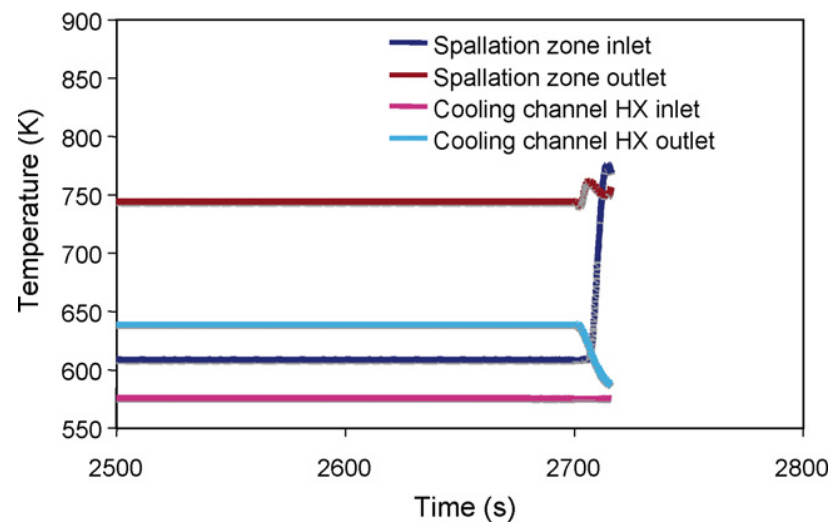

Fig. 20. Spallation zone and cooling channel inlet and outlet temperatures.

the power deposition occurs (vol. 209, 210). The primary LBE temperature at the HX inlet is, instead, always constant and the outlet temperature decreases due to the heat exchange degradation for the HX pipe side flow rate interruption, Fig. 20. The primary LBE flow rate in the cooling channel, shown in Fig. 19, consequently decreases after the second pump trip. The core inlet and outlet temperatures remain at their original value, as no flow variation occurred in the primary system.

In order to verify the onset of flow instabilities or possible local effects due to the buoyancy force that should be strengthened by the lower mass flow rate, a STAR-CD calculation was performed after the first pump trip. The results are reported in Figs. 22-24. Fig. 22 reports the temperature difference between any fluid location and the inlet, as any flow instability depends directly on the fluid temperature variation and not on its absolute value. Figs. 23 and 24 show the corresponding relative pressure field and the velocity magnitude map, respectively.

The main flow characteristics for the new steady state conditions achieved after the pump trip and for the initial conditions are summarized in Table 4 . The new steady state flow rate is a little larger than that calculated by RELAP5 (difference $0.3 \mathrm{~kg} / \mathrm{s}$ ).

All these fields exhibit a very strong similitude with the nominal flow rate fields, indicating no onset of buoyancy driven instability or local effects. Furthermore the temperature variations scale in good approximation with the inverse of the mass

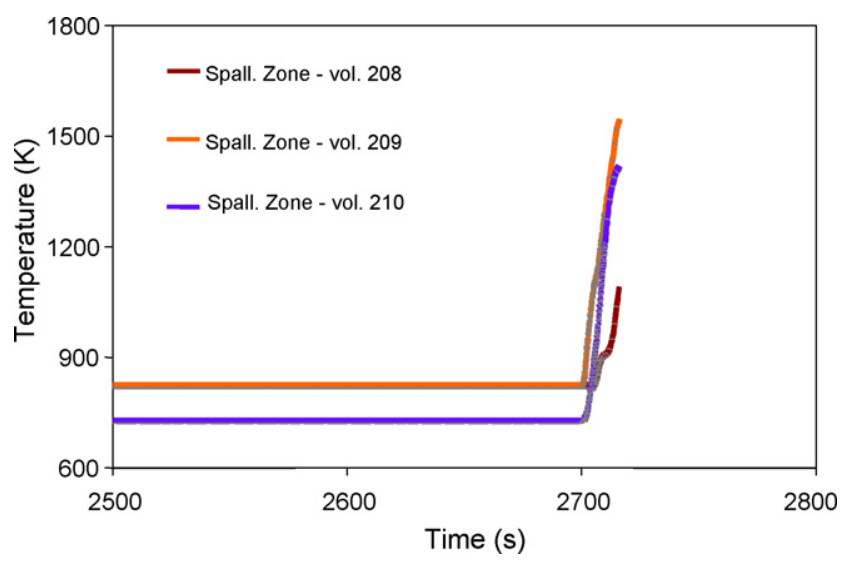

Fig. 21. Spallation zone temperatures.

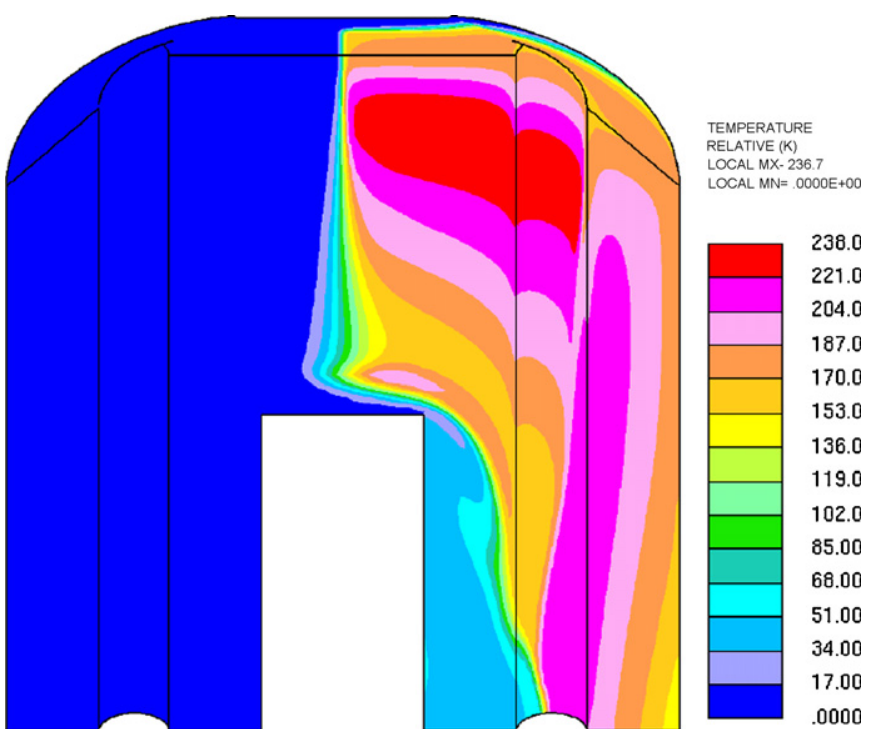

Fig. 22. Pump trip: temperatures map.

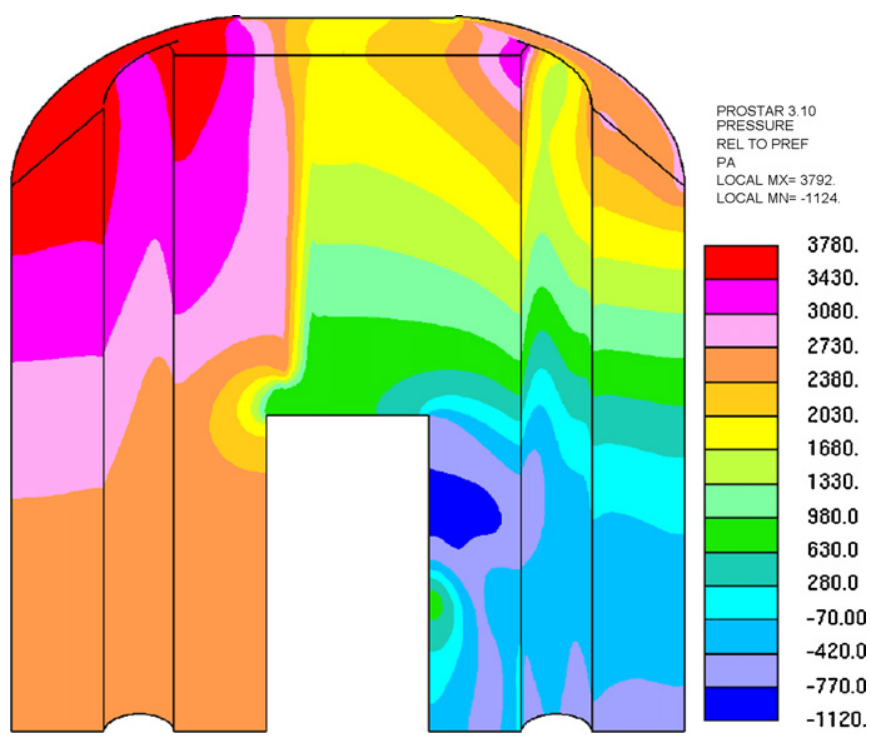

Fig. 23. Pump trip: relative pressures map (without the hydrostatic component).

flow rate and the pressure with its square confirming once again a small influence of the buoyancy at this reduced regime. This result is in apparent contradiction with the thermal stratification foreseen by RELAP5. That can be explained considering that the thermal stratification depends on the interaction between the heat release and the flow field and that in STAR-CD simulation the flow field was evaluated with a much finer scale than that used

Table 4

Main flow characteristics at full power and after the first pump trip

\begin{tabular}{llc}
\hline Parameter & Steady state & Reduced flow \\
\hline Mass flow rate $(\mathrm{kg} / \mathrm{s})$ & 207 & $\sim 132$ \\
Maximum bulk temperature- $T_{\mathrm{in}}{ }^{\mathrm{a}}(\mathrm{K})$ & 146 & 237 \\
Maximum surface temperature- $T_{\text {in }}(\mathrm{K})$ & 104 & 174 \\
Mean relative pressure $(\mathrm{KPa})$ & 6.1 & 3.0 \\
\hline
\end{tabular}

${ }^{\text {a }} T_{\text {in }}$ is the inlet temperature in the modelled zone with STAR-CD.

Please cite this article in press as: Bianchi, F., et al., Thermo-hydraulic analysis of the windowless target system, Nucl Eng Des (2008), doi:10.1016/j.nucengdes.2007.10.026 


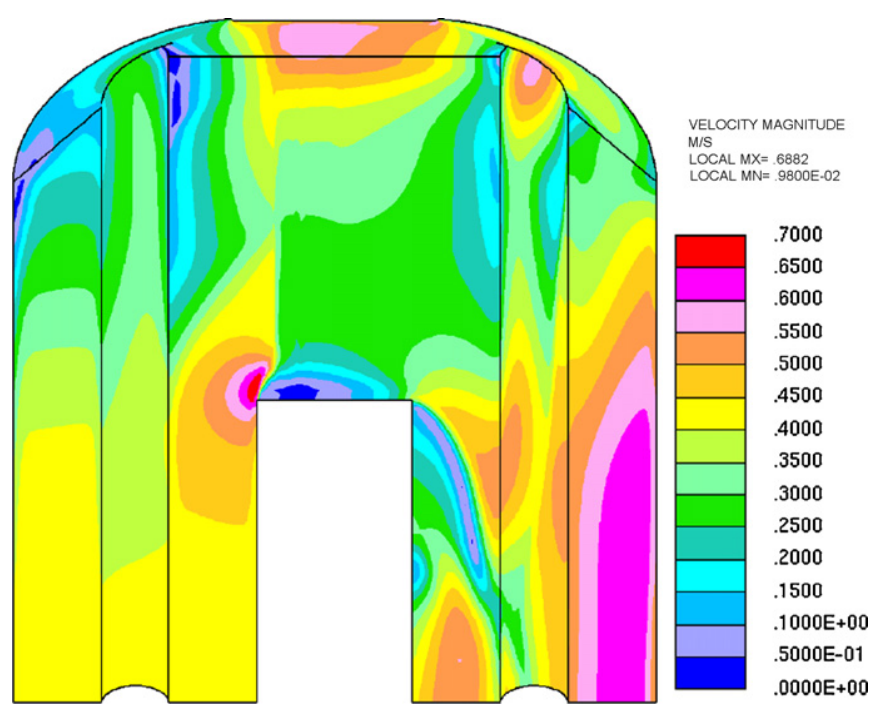

Fig. 24. Pump trip: map of velocities magnitude.

with RELAP5. Moreover the steady state thermo-hydraulic sizing of the modelled zone with STAR-CD code was performed imposing that the vertical component of the LBE velocity at the spallation zone inlet is completely damped and tailoring the axial flow rate profile so that to counterbalance the variable heat deposition along the beam range.

The analysis of this accident shows that, if the flow is not sufficiently tailored, the loss of a pump ( 1 out of 2 ) may provoke a thermal stratification in the spallation zone if the accelerator beam is not shut-off. In case also the second pump fails, the time of intervention for operators is very short.

\section{Conclusions}

A series of transient sequences was simulated to investigate its impact on the whole plant and the target system and to define enveloping conditions to be used for thermo-mechanical verifications. The accidental transients analysed concern the accelerator beam trips of different duration, the trip of one pump with and without the accelerator beam shut-off and the trip of the two pumps without the accelerator beam shut-off.

The analysis of beam trips showed that their time length has to be not larger than $1 \mathrm{~s}$ to avoid heavy thermal stresses on the walls of the target structures.
The study of the pump trip followed by the beam shut-off highlighted that this accidental sequence does not have any consequences on the target and plant. Instead, if the beam shut-off does not occur, the target might be largely impaired by the thermal stratification occurring in the spallation zone due to the flow rate reduction and the power supply, mostly in case the flow distribution is not properly tailored. In case of the two pump trip without beam shut-off, the period of grace for the operators is very short, but this accident is characterized by a very low probability of occurrence.

\section{Acknowledgments}

This work was partially funded by the EU program PDSXADS, contract No. FIKW-CT-2001-00179.

\section{References}

Bianchi, F., Ambrosini, W., et al., 2002. Natural circulation of lead-bismuth in a one-dimensional loop: experiments and code predictions. In: Proceedings of the 10th International Conference on Nuclear Engineering, ASME, Arlington, VA, USA, ICONE10-22356.

Bianchi, F., et al., 2004. Lead-bismuth eutectic cooled experimental accelerator driven system: windowless target unit thermal-hydraulic analysis. In: Proceedings of the International Conference on Nuclear Energy for New Europe 2004, NSS, Portoroz, Slovenia, p. 720.

Bianchi, F., et al., 2006. Status and trend of core design activities for heavy metal cooled accelerator driven system. Energy Convers. Manage. 47, 2698-2709.

Carluec, B., 2003. The European project PDS-XADS—preliminary design studies of an experimental accelerator driven system. In: Proceedings of the International Workshop on P\&T and ADS Development, SCK-CEN, Mol, Belgium, p. A91.

Carluec, B., Jardì, X., 2003. European project PDS XADS—accelerator driven system: engineering activities. In: Proceedings of the International Congress on Advances in Nuclear Power Plants, Senda Editorial SA, Cordoba, Spain.

Cinotti, L., Gherardi, G., et al., 2003a. XADS cooled by Pb-Bi system description. In: Proceedings of the International Workshop on P\&T and ADS Development, SCK-CEN, Mol, Belgium, p. A59.

Cinotti, L., et al., 2003b. Design of a windowless target unit for the XADS lead-bismuth coolant system. In: Proceedings of the International Workshop on P\&T and ADS Development, SCK-CEN, Mol, Belgium, p. A80.

EI-Boher, A., et al., 1988. Experimental studies of liquid metal two phase flows in vertical pipes. In: 1st World Conference on Experimental Heat Transfer, Fluid-Mechanics and Thermodynamics, Dubrovnik, Yugoslavia.

Rubbia, C., et al., 2001. A European roadmap for developing accelerator driven system (ADS) for nuclear waste incineration. ENEA, Rome, Italy, ISBN: 88-8286-008-6.

Shich, A.S., et al., 1998. RELAP5/MOD3 Code Manual vol. II: User's Guide and Input Requirements, USNRC Report, NUREG/CR-5535. 